TITLE:

\title{
COLLEMBOLAN FAUNA OF THE CAPE PROVINCE, WITH SPECIAL REFERENCE TO THE GENUS SEIRA LUBBOCK
}

AUTHOR(S):

Yosii, Riozo

CITATION:

Yosii, Riozo. COLLEMBOLAN FAUNA OF THE CAPE PROVINCE, WITH SPECIAL REFERENCE TO THE GENUS SEIRA LUBBOCK. SPECIAL PUBLICATIONS FROM THE SETO MARINE BIOLOGICAL LABORATORY 1959, 1(6): 1-24

ISSUE DATE:

1959-06

URL:

http://hdl.handle.net/2433/176436

RIGHT: 
SPECIAL PUBLICATIONS FROM THE SETO MARINE BIOLOGICAL LABORATORY

\author{
BIOLOGICAL RESULTS \\ $\mathrm{OF}$
}

THE JAPANESE ANTARCTIC RESEARCH EXPEDITION

6.

COLLEMBOLAN FAUNA OF THE CAPE PROVINCE, WITH SPECIAL REFERENCE TO

THE GENUS SEIRA LUBBOCK

BY

RIOZO YOSII

YOSHIDA COLLEGE, KYOTO UNIVERSITY

KYOTO, JAPAN

SIRAHAMA, WAKAYAMA-KEN

J A P A N

JUNE 1959 
SPECIAL PUBLICATIONS FROM THE SETO MARINE BIOLOGICAL LABORATORY

BIOLOGICAL RESULTS

$\mathrm{OF}$

THE JAPANESE ANTARCTIC RESEARCH EXPEDITION

6.

COLLEMBOLAN FAUNA OF THE CAPE PROVINCE, WITH SPECIAL REFERENCE TO

THE GENUS SEIRA LUBBOCK

BY

RIOZO YOSII

YOSHIDA COLLEGE, KYOTO UNIVERSITY
KYOTO JAPAN

SIRAHAMA, WAKAYAMA-KEN

J A P A N

JUNE 1959 
THIS SERIES contains THE BIOLOGICAL RESULTS OF THE JAPANESE ANT ARCTIC RESEARCH EXPEDITION and is published by the Seto Marine Biological Laboratory. Parts will appear at irregular intervals as they become ready. 
DURING my stay in Cape Town on our way to and from the Antarctic, in the year 1957-1958, I have had good opportunities to collect collembolan materials of its vicinity. As it was a dry season of the year at that time, I was unable to check all forms already known from the district. Yet it is with great pleasure that I could come in contact with various forms of Seira, a genus which seems to be predominant for the collembolan fauna of the African continent.

In the course of my excursion, I was kindly helped by many scientists: Prof. Mr. and Mrs. Rowan of the Fishery Institute, Prof. DAy of the Zoological Institute in the University of Cape Town, Mr. and Mrs. GARST and others to whom my sincere thanks are directed. I also express my indebtedness to all members of the JARE Expedition with the Leader Prof. T. NAGATA and to all crews of the "SÔYA" with the Captain M. MATSumoto.

\section{Choreutinula lobata sp. n.}

(Fig. 1)

2 males from Table Mountain, 11. III 1958.

Body length $0.7 \mathrm{~mm}$. Colour entirely white with the exception of black eye pigments. Ant./Head as 8:9. Antennal ratio as 6:6:9:9. Distal two segments are clavated. Ant. IV with a prominent apical bulb inserted within the segment. Some 6 curved sensory setae are present. Ant. III-organ composed of two pairs of sensory bulbs in a common furrow of the integument. The outer pair of them is larger than the inner pair. One curved seta near the outer side of them seems to be also of sensory nature in appearance. Ant. II and I is with a row of small setae. Eyes 5+5, each separately pigmented. Postantennal organ is composed of one large central tubercle whose marginal portion is divided irregularly into four lobes. Mandible well represented and with finely toothed molar parts. Maxilla lamellated and toothed apically, as usual for the genus. Legs feebly developed. Unguis subtriangular in lateral view and without any tooth. Both unguiculus and tenent hair seems to be absent. Tibiotarsus is annulated on their distal part. Ventral tube with $4+4$ setae. Tenaculum with 3 toothed rami. Furcula well developed. Manubrium almost smooth. Dentes dorsally granulated, distally converging and with 4 dorsal setae. $\mathrm{D}: \mathrm{Mu}$ as $18: 10$. Mucro straight, ending 
with a little rounded apex and with somewhat broad inner lamella stretching from the base until to a little before the apical bulb, where it terminates abruptly. Male genital area is rounded, with many minute setae. Anal spines absent. Integuments are coarsely granular. All body setae are small and subequal. S. s. is not at all differentiated. Their arrangement is as in Fig. 1, J.

The species is near C. libyca (CARol, 1914) from Tripoli and Europe (England, France), but separated from it readily by distincly lobated post-

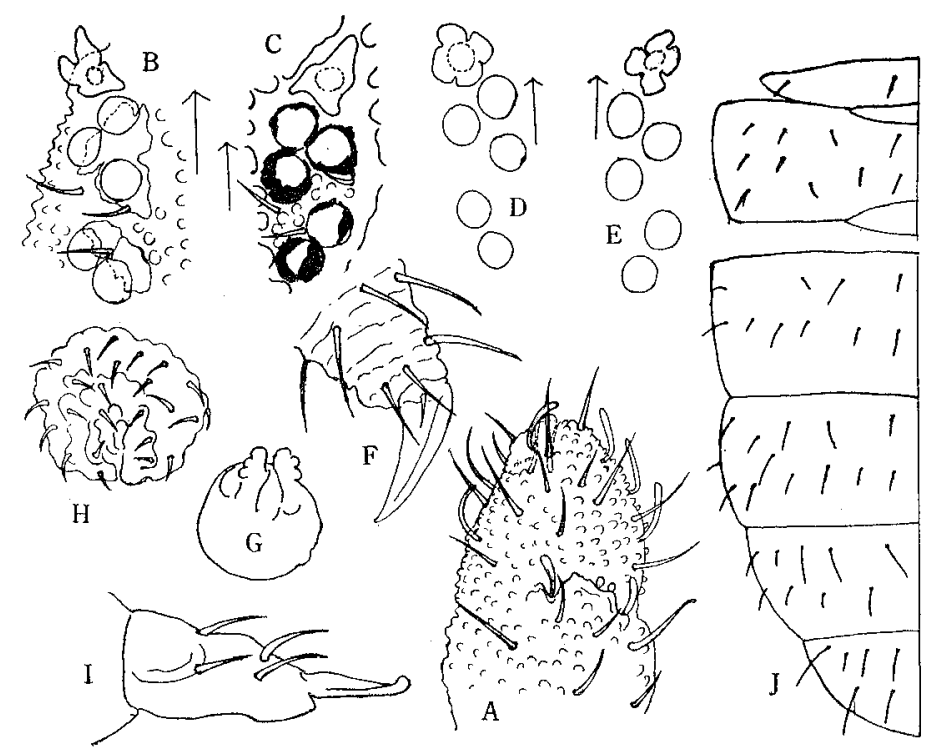

Fig. 1. Choreutinula lobata sp. n.

A. End of antenna, B. C. D. E. Eyes and postantennal organ, F. Hind leg, G. Tenaculum, H. Male genital field, I. Dentes and mucro, J. Chaetotaxy of body segments.

antennal organ and lamellated mucro. With respect to the former character, the species reminds us the Genus Schoettella, but the arrangement of the body setae reveals its belonging to Choreutinula. The setae on Th. I is $3+3$ in Schoettella and $2+2$ in Choreutinula. Those of Th. II, III and Abd. IV are in three transverse rows in Schoettella, while they are in two rows in Choreutinula in dorsal groups.

Brachstomella parvula africana ssp. $\mathrm{n}$.

(Fig. 2)

Syn. B. parvula, WOMERsLey 1933.

12 Examples from Kloof Nek, 4. XII 1957. 
They coincide in all major characters to the principal species described by STACH (1949) on Polish materials. But the apical bulb of Ant. IV is not trilobed but merely circular. Length of the body is $0.8 \mathrm{~mm}$. Colour bluish grey. Postantennal organ is composed of 6 elements. $8+8$ eyes are independently pigmented. Unguis with one inner tooth. Tenent hair not knobbed. Ventral

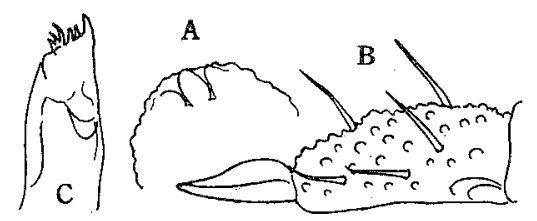

Fig. 2. Brachystomella parvula africana ssp. n.

A. End of antenna, B. Dentes and mucro,

C. Head of maxilla.

tube with $3+3$ hairs. Tenaculum with 3 toothed rami. Dental setae 5 . Dentes granulated. Mucro almost straight and tapering to the apex. Its outer lamella is broader than the inner one. Chaetotaxically, the form coincides well with the description and figure of GISIN (1957) from Switzerland with regards to $\mathrm{Abd}$. $\mathrm{V}$.

\section{Anurida maritima LABOULBENE}

30 examples from Sea Point, 11. III 1958.

Ballistura schötti (DALla TORRE)

(Fig. 3)

25 Examples from the beach of the Rondevlie Marsh, 10. III 1958.

Body length up to $1.0 \mathrm{~mm}$. Colour bluish grey. Head and trunk is symmetrically mottled with yellowish tinge, which is the ground colour of the body. Anterior half of the head and fore margin of each segment are depicted. Th. II-Abd. IV has also each a pair of such decoloured spots. Antennae diffusely pigmented. Legs and furcula pale. Antennal ratio as 13:15:16:22. Ant. III has distally two typical sensory rods in a groove and one curved sensilla on the outer side. Two or three curved setae, alike to sensillae are situated on the inner side of these rods. Postantennal organ subovate, not constricted and about a diameter of an eye. Eye field black. $8+8$ eyes are subequal, but $\mathrm{G}$ and $\mathrm{H}$ are a little smaller than others. Tibiotarsus with a subsegment near the unguis. Unguis slender, untoothed. Unguiculus slightly arcuated and with a terminal portion extending to a filament to some length. 
Tenent hair absent. Ventral tube with $1+1$ anterior and $1+1$ posterior setae. Tenaculum with 3 toothed rami and with 1 seta on corpus. Furcula reaching to the middle of Abd. II. Man: D:Mu as $15: 10: 2$. Manubrium with many ventral setae. Dentes rod-shaped, not much converging to the end, with many feeble setae all along the dorsal side and with some setae upon distal $2 / 3$ of

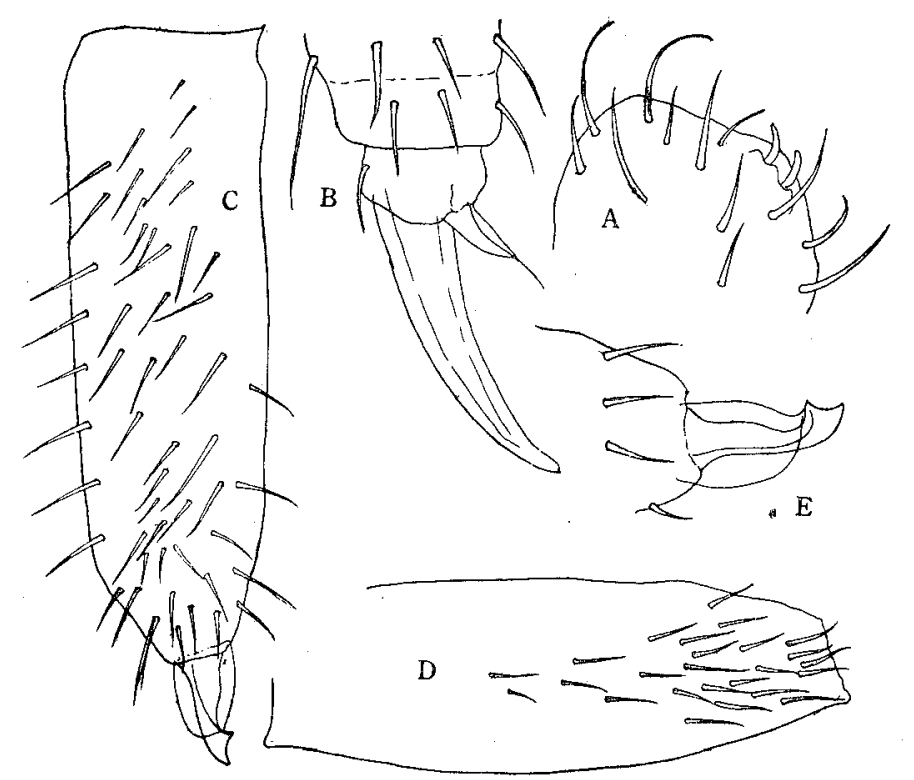

Fig. 3. Ballistura schötti (DAlla TORRE).

A. Ant. III-organ, B. Hind claw, C. Dentes (dorsal view),

D. Dentes (ventral view), E. Mucro.

the ventral side. Mucro curving, ending in two subequal teeth. A pair of broad mucronal lamella is extending from the anteapical tooth to the mucronal basis. Body hairs polychaetotic. All of them are subequal but a little longer posteriorly.

Notes: This is the first reliable record of the species from Africa. YosIr's record of B. schötti in 1939 from Japan represents, as has been already pointed out by DENIS (1948) and STACII (1947), an independent species: Proisotoma yosii STACH, 1947.

\section{Entomobrya sp. (cf. nivalis L.)}

4 Examples from Kloof Nek, 5. XII 1957.

They are referable to E. nivalis LinNé with its pattern of the body. But the exact identification is not possible because I have only females of relatively young stage. 


\section{Pseudosinella cf. candida FoLSOM}

(Fig. 4)

31 examples from Kloof Nek, 5. XII 1957.

Body length up to $1.5 \mathrm{~mm}$. Ground colour white. But as all the body surface is covered densely with minute blue spots, it is grayish blue in appearance. Marginal parts of each tergite are pale, owing to the lack of these spots. Antennae and area verticalis of the head are deeply coloured bluish gray. Eyes intensely black. Legs and furcula slightly coloured on their proximal portion. Antennae subequal to head in length. Antennal. segments in relaterion as $14: 27: 23: 43$. Ant. IV without apical bulb. Ant. III-organ is a pair of blunt rod-like setae, accompanied by two slender simple setae and one short peg-like organ exterior to them. Eyes $8+8$. Mesonotum

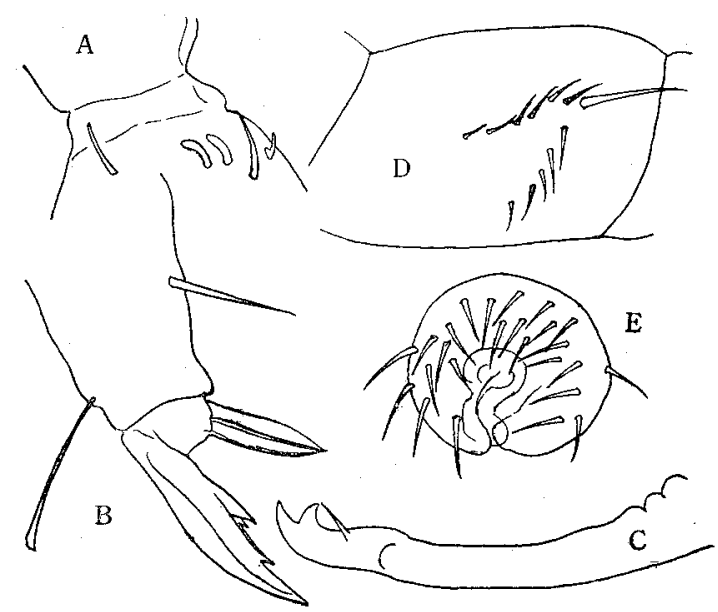

Fig. 4. Pseudosinella cf. candida Folsom.

A. Ant. III-organ, B. Hind claw, C. Mucro, D. Trochanteral organ, E. Male genital field.

moderately protruded over the head. Unguis slender with a pair of basal inner tooth well developed and unequal in shape. A median distal inner tooth is very conspicuous. Unguiculus lanceolate, without tooth, but with a broad outer lamella. Tenent hair feeble, shorter than the unguis and with apex slightly swollen or sometimes simply blunt. Trochanteral organ composed of 6-7 longitudinal and 5-6 transverse setae in L-shape. A seta at the corner is stronger than others. Tenaculum with 4 -toothed rami and one seta. Furca well developed. Manubrium subequal to dentes in length. Both without any special structure. Mucro 2-toothed and with one basal spine. 
Notes: African examples differ from Forsom's description in its body colour. But as they are equal in other details, they must be regarded for the moment as conspecific with the American forms described from the grave of New York city. Pseudosinella usitata Folsom (1927) from the Middle America is pigmented as in the present form, but differs in having no median tooth of the unguis.

\section{Lepidocyrtus cf. lanuginosus (GMELIN)}

10 examples from Table Mountains, 5. XII 1957.

Notes: Compared with European examples of the species, African forms have the body scales more prominently brownish in colour, although there exists no specific difference between them. Lepidocyrtus lanuginosus var. ceratoxenus BÖRNER (1907) from East Africa must belong to the same category.

\section{Seira LuBBOCK 1867}

Entomobryoid in appearance. Antennae either moderately long and not annulated or extremely long and obviously annulated with all transient forms between them. Ant. IV with minute apical bulbs. Ant. III-organ is a paired rod-like sensillae. Eyes $8+8$. Mesonotum somewhat protruded over the head. Unguis slender, with a pair of inner proximal and one inner distal tooth. Dorsally, a dorsal tooth is accompanied by a paired pseudonychia-like lateral teeth. All of them are subequally large. Unguiculus lanceolate, without or with a minute outer tooth. Its outer margin is often serrated on fore-legs. Trochanteral organ well developed in species with great body size, but seemingly augmenting the number of setae during the growth. Maximal number of setae observed are 72. Tenaculum with 4-toothed rami and one feathered seta on corpus. Furcula well developed. Its dorsal side is often with special structures or with specially modified setae. Dental crenulation is ending abruptly leaving a smooth portion about 2-3 times the length of the mucro, which is falciform and without basal spine. Male genital opening is conically protruded and surrounded with a row of some 20 small setae.

Body surface is covered with large scales, usually brownish in colour. They are rounded and oval, alike to those Lepidocyrtus but coarsely sculptured as in Willowsia. Scales from the ventral side of dentes are oval and small in S. rowani but spindle-shaped and large in most of species. Antennal segments are scaled until to Ant. III at least. Tibiotarsus always scaled. Chaetotaxy of the trunk is heterochaetotic and large brushed setae are relatively few in number. Their arrangement on each tergite is constant in a given species and affords good reliable character for the identification of each species. Upon mesothorax, they are divided in three groups: the anterior group forms a "collette" around the fore margin of the trunk. They are numerous and not to be used for the purpose. Those of the middle and posterior group (Th. II m, Th. II p) are useful just as those of Th. III-Abd. II. On Abd. I, 
4-5 setae are arranged in a transverse row. In some species, they are almost in a straight line (S. dayi), but sometimes, one, of them is located slightly anterior to others (no. 2 by S. nagatai and pseudocoerulea, no. 3 by annulicornis). Abd. II has either 3 or 4 pairs of such setae and its arrangement is L-shaped or in a straight line, according to the species. Those of Abd. III is not specific in all forms, while those of Abd. IV is characteristic for each species. Setae sensuales (=) bothriothryx) are distributed upon Abd. II-IV in 2, 3, 3 pairs (excl. S. rowani) as was already mentioned by DENIs (1924) upon S. domestica NICOLET of France. This is a rather exceptional number of s. s. as all other members of Entomobryidae have 2, 3,2 pairs of them (Yosil, 1956). In inspecting these s. s., I have come across to the fact that the most posterior pair of s. s. upon Abd. IV is exceptionally without the accessory small setae or scales, which surround the place of insertion of these s. s. and, therefore, not equivalent to other pairs. In S. rowani, Abd. IV has only 2 pairs of s. s. near the posterior margin of the segment, all of them having well developed accessory setae. For this reason, I have erected a new subgenus: Afroseira to accommodate the species.

The genus Seira has many synonymic names: Pseudosira ScHöтT (1893) erected for $P$. elegans from Cameroon is dubious, because he has regarded Seira LuBBock (=Sira) having two toothed mucro. Mesira STACHERBAKov (1898), erected for $M$. squamoornata from Ukraina is perhaps identical with Seira s. str.. Lepidocyrtinus BÖRNER (1903) was erected for Lep. annulicornis from Nyassa on the basis that the antennae are annulated. The annulation of antennae is, however, not always a reliable character, because we have many intermediate forms, whose antennae are slightly annulated or only implicited by ring arrangement of setae. Furthermore, juvenile forms of Seira are always not annulated with regards to their antennae, so that the great confusion occurs by using it as one of generic characters. The genotypical species: $L$. annulicornis has, on the other hand, many peculiarly modified blunt setae along the dorsal side of the dentes and this character is restricted only for the group of Seira species from the eastern and southern Africa, including.

Seira annulicornis (BÖRNER, 1903)

Seira barnardi (WOMERSLEY, 1933)

Seira laeta (BÖRnER, 1908)

Seira armillata (WAHLGRen, 1908) (sens. Delamare Deboutteville, 1954)

Seira voeltzkovi BÖRNER, 1907

Seira dayi sp. $\mathrm{n}$.

Lepidocyrimus BÖRnER can, therefore, be regarded as a subgenus of Seira from these new view point. As Pseudosira elegans ScHöt is near Seira barnardi in its body colour, it may be, that elegans has also such modified setae upon dentes. In this case, Lepidocyrtinus (1903) is preoccupied by 
Pseudosira (1898). Drepanocyrtus HANDSCHIN (1925) is, in all probability, identical with Seira s. str. as was already cited by HaNDSCHIN (1924) himself.

In short, the genus Seira is to be divided in three subgenera in the following manner:

\author{
Seira LubBock (1867) \\ Genotype: Seira domestica NrColet (1841)
}

1. Subgenus Afroseira nov.

Abd. IV with $2+2$ s. s. Dentes with basal swelling.

Subgenotypus: Seira rowani sp. n.

2. Subgenus Lepidocyrtinus BÖRNER (1903)

Abd. IV with $3+3$ s. s. Dentes with blunt modified setae.

Subgenotypus: Lepidocyrtinus annulicornis BÖRNER. (1903)

3. Subgenus Seira s. str.

Subgenotypus: Seira domestica Nicolet (1841)

There has been described more than 50 species of Seira s. lat. from all parts of the world, especially from tropical and southern countries, although there has been given very few reliable characters to divide each of them. As their chaetotaxy on the body segments to discriminate each of these species are unknown, all of them must be revised. In the present paper, I have illustrated $S$. ferrarii PARONA in addendum.

Seira (Lepidocyrtinus) annulicornis (BöRNER)

(Fig. 5)

8 examples from the top of the Table Mountain, 11. III 1958.

Body length up to $3.3 \mathrm{~mm}$. Ground colour white, somewhat brownish by dense clothing of scales. Antennae violet upon distal two segments. Ant. II is pigmented either on its distal end or along its dorsal side. Ant. I pale. Eye field black. Antennal basis also pigmented. Light purplish pigments appear on distal end of femur on mid- and hind legs. Other parts of the body are pale. Antennae long, being about 4- times the diagonal of the head. Their relative length is as $10: 15: 22: 20$, so that Ant. III is longer than Ant. IV. Distal two segments are well annulated as in the case of Tomocerus. Small scales are present from its basis until to the middle of Ant. III, where annulation begins. Unguis with a pair of inner basal tooth at about the middle and an unpaired inner distal tooth, where two ridges are converging. An additional small tooth may be present or absent. Dorsal side of the unguis is provided with pseudonychia-like three dorsal teeth, one of which, lying on the outer side of the unguis is well developed and attains $1 / 3$ of the unguis. Unguiculus lanceolate, acuminate to the end. Tenent hair well developed, 
subequal to the unguis in length and with flattened end. Trochanteral organ of the hind leg is composed of about 60 short setae. Dentes of the furcula with numerous upright blunt setae in a row along the inner dorsal margin of

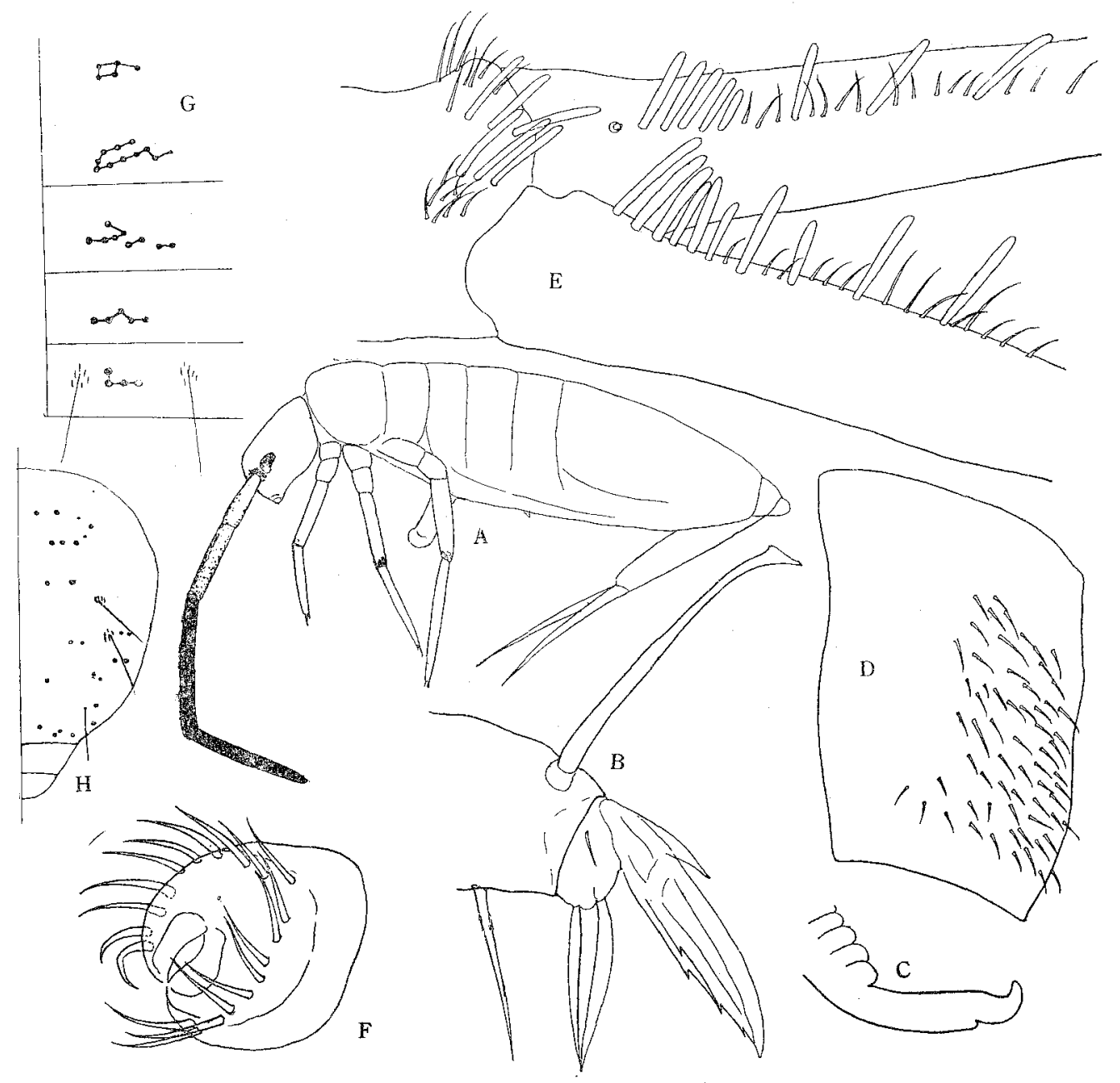

Fig. 5. Seira (Lepidocyrtinus) annuticornis (BöRNER).

A. Habitus, B. Hind claw, C. Mucro, D. Trochanteral organ, E. Manubrium and dentes with blunt setae, F. Male genital field, G. Chaetotaxy of body segments (diagramatic), H. Chaetotaxy of Abd. IV.

the crenulated zone. Near the manubrial end, some six of them are standing so closely side by side that it is comb-like in appearance. $3+3$ dorsal setae at the dental end of the manubrium are also converted to such claviform blunt 
setae, a feature rather peculiar for the species. Male genital field is a rounded elevation and its opening is surrounded with about 20 simple setae of equal length. Feathered setae are arranged as figured. Setae of s. s. are accompanied by some very narrow special scales, which are some very narrow special scales, sometimes barbellated at the end.

Notes: It is only from the general trend of the genus, that I have identified the present form to BÖRNER's species, which is first described from Nyassaland. As nothing is known about the arrangement of claviform setae upon dentes and manubrium of the type specimens, further study must be expected.

\section{Seira (Lepidocyrtinus) barnardi (WOMERSLEY)}

(Fig. 6)

Syn.: Lepidocyrtinus cooperi var. barnardi WOMERSLEY 1933.

47 examples from Kirstenbosch, 10. III 1938.

Body length up to $2.8 \mathrm{~mm}$. Ground colour yellowish white, but the body has some brownish appearance owing to dense body scales. Distal portion of Ant. II and all length of Ant. III and IV are violet in colour. Purplish black pigments form a pattern of the body as in Fig. 6, A and these pattern is almost constant in all examples examined. Antennae long, being about 3.5 times the diagonal of the head. Antennal ratio is as $10: 14: 28: 21$, so that Ant. IV is shorter than Ant. III. Antennae scaled from the base until to the proximal portion of Ant. III. Ant. IV with two small apical bulbs. Ant. IIIorgan is a pair of short rods situating on the outer side of its distal end. Ant. IV and the distal 3/4 of Ant. III are seemingly annulated, although there exists no real subsegmentation as in the case of Tomocerus and the structure extinguishes by long exposure of the example in lactic acid. Eyes $8+8$, intensely black. A median spot is present between antennal basis. The heavily scaled tibiotarsus bears usually a long seta on its proximal portion. Some setae along the posterior margin of the tibiotarsus are also long. Trochanteral organ of the hind leg is well developed and with about 60 setae in full grown examples, while the number diminishes considerably in smaller ones. Tenent hair well developed and distally dilatated. Unguis and unguiculus normally built for the genus. Dentes of the furcula with dorsal crenulation until to a little before the mucro, where it is abruptly terminated. Along the inner side of the crenulation, there exists dorsally a row of blunt, rod-like setae on its proximal half of its length. Each seta is somewhat bacilliform, hyaline and slightly ciliated on all sides. They are not always on the same row with normal ciliated setae, but sometimes occuring from the inner side of the row. They are, therefore, more irregular in arrangement than in the case of $S$. annulicornis and no exact formula is to be expressed. 
Lateral part of the dentes are with numerous filiform, finely ciliated setae and its ventral side is well beset with rounded scales. Genital opening of the male is surrounded by some 14 small setae upon a conically protruded heap of the area. These setae are not especially differentiated. Chaetotaxy of the

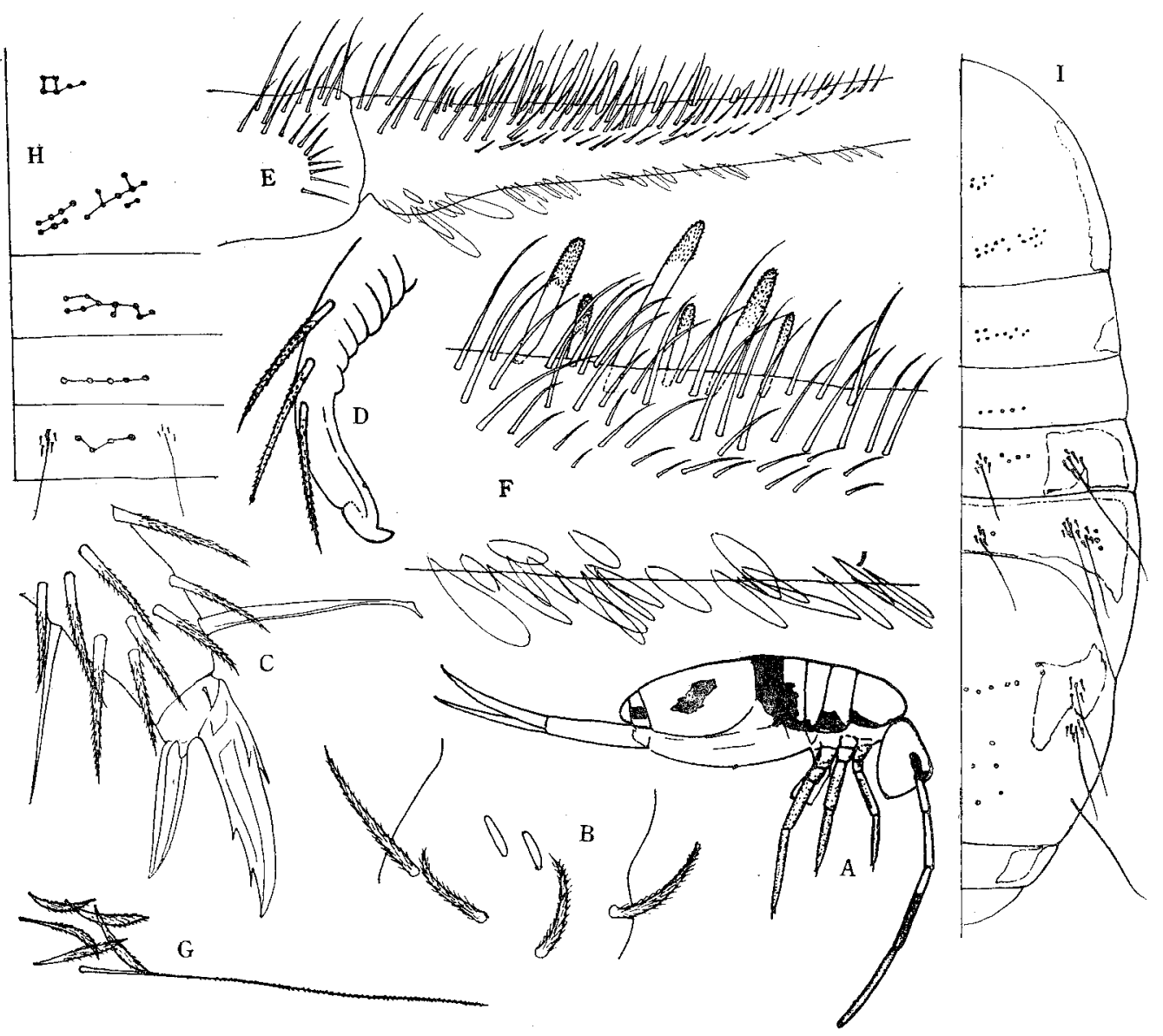

Fig. 6. Seira (Lepidocyrtinus) barnardi (WOMERSLEY).

A. Habitus, B. Ant. III-organ, C. Hind claw, D. Mucro, E. Dentes, F. Blunt setae of dentes, G. Seta sensualis with accessory scales, H. Chaetotaxy of body segments (diagramatic), I. Chaetotaxy of all body segments.

feathered setae of the body as shown in Fig. $6 \mathrm{G}$, H. Setae sensuales are accompanied by some 5-6 narrowly lanceolate scales of special type, which surround the inserting place of $\mathrm{s}$. $\mathrm{s}$.

Notes: In the colouration of the body, the present form is near Seira cooperi from Abyssinia as has been stated by WOMERSLEY. But as we do not know the real nature of the cited species, it is better to place the form independently. Seira elegans (SCHÖTT) and Seira nyassica (Börner) have also some 


\section{Riozo YosiI}

resemblances to the species in this respect. The blunt dental setae which are first mentioned and figured by C. Börner $(1907,1909)$ in his Pseudosira voeltzkowi from Madagaskar and Pseudosira laeta from Klein-Namaland has been reported also by SALMON (1956) in his Mesira squamoornata STSCHERBAKov from Ruanda Urundi and he synonymized Börner's $P$. laeta with STscherBAKOv's species. I myself can not come in accordance with SALMON's opininn, since Mesira squamoornata is described from Kiew in 1898 without notion whether the blunt dental setae exist or not. The Mediterranean forms of Seira, which is once regarded as P. squamoornata by HANDSchin (1942) have no such setae at all.

Seira (Lepidocyrtinus) dayi sp. nov.

(Fig. 7)

3 examples from Skeleton Gorge, 6. XII 1957.

Body length $1.8 \mathrm{~mm}$. Ground colour brownish white. Antennae diffusely pigmented to reddish purple on their whole length. Eyes black. Head pig. mented only along its fore margin. Antennal base pale. All body segments
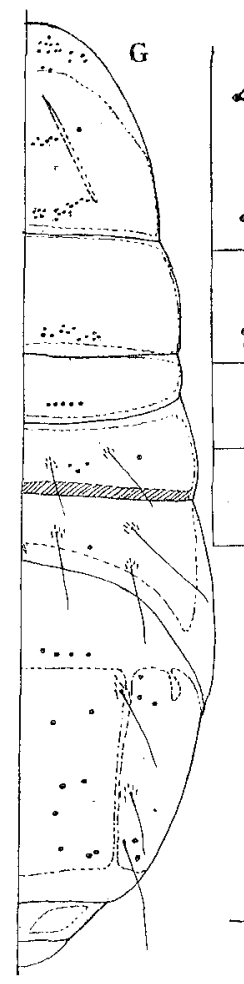

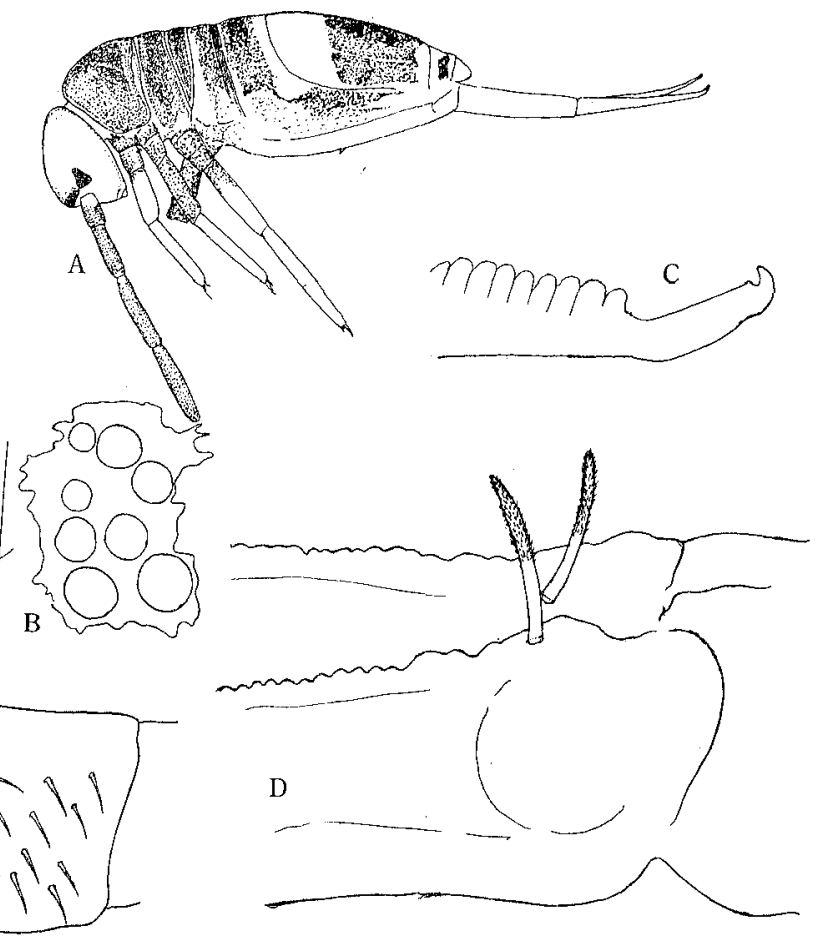

Fig. 7. Seira (Lepidocyrtinus) dayi sp. n.

A. Habitus, B. Eye-field, C. Mucro, D. Dentes with blunt setae, Chaetotaxy of body segments (diagrammatic), G. Ditto.

E. Trochanteral organ, F. 
are densely mottled with purplish pigments leaving their fore and hind margins uncoloured. Along the hind margin of Th. III-Abd. II, a narrow transverse band of the same colour is observed. Proximal one-third of Abd. IV is broadly depicted. So is also the hind margin of the same segment and posterior segments of the abdomen. Fore legs purplish on their coxal and trochanteral segments, while other two legs are intensely pigmented until to the middle of the femur. Ventral tube deeply pigmented, while ventral parts of the body and proximal half of the furca only slightly coloured. Scales are rounded and rather brownish than in other species of the genus. Antennae relatively short, being about 2.5 times the length of the head. Their segmental ratio is as $10: 18: 20: 25$. Ant. IV with two obscure apical bulbs. Ant. III and IV are apparently not annulated. Scales are observed until to the proximal portion of Ant. III. Eyes 8+8, unequal in diameter. Unguis with a pair of inner basal and one inner distal teeth. Dorsal teeth are also well represented. Unguiculus lanceolate and untoothed. Tenent hair normal for the genus. Trochanteral organ of the hind leg represented by some 20 short setae. Dentes of the furcula without a row of blunt setae but instead, with one feathered seta, which is, although subequal in length, distinctly more robust in profile than the neighbouring setae of the dentes. Dorsal crenulation of dentes and the shap of the mucro is as usual. Brushed setae of the body is arranged as in Fig. 7 F, G. Those of Abd. I and II are very characteristic. Some of the companion scales of $\mathrm{s}$. s. and especially those of Abd. II and III are not scales but reduced to small feathered setae.

Notes: The species is named in honour of Prof. DAY of the University of Cape Town. It is somewhat close to Pseudosira grisea var. annulata WoMERsLey (1933), but the dental adornment is naturally unknown for the cited form. The species with a single blunt seta upon dentes is already known from Port Nolloth as Pseudosira laeta BöRNER (1908), from which the species is different in colouration of the body.

\section{Seira (Afroseira) rowani sp. nov.}

(Fig. 8)

18 examples from the top of the Table Mountain, 11. III 1958.

Body length $2.2 \mathrm{~mm}$. Ground colour whitish, adorned by beautiful purplish pigments as in Fig. $8 \mathrm{~A}$. Intensely pigmented are the antennal basis and both sides of thoracic segments. Head with a longitudinal stripe from the eye-patch backwards. Body segments each with a row of lateral stripe and a broad median stripe, which shows considerable irregularities especially upon abdominal segments. Antennae reddish violet throughout their length. Legs are banded upon femur and on the middle portion of tibiotarsus. Ventral tube and furcula pale. Antennae very long, being more than 6 times the diagonal of head in length and longer than the body. Antennal ratio as 
$10: 15: 38: 69$, so that Ant. IV much longer than Ant. III. Ant. I, II and the proximal half of Ant. III scaled. Ant. III and IV strongly annulated as in the case of Tomocerus. An obscure apical bulb is present. Ant. III-organ normally built. Eyes $8+8$, upon black patches. Legs scaled until to the end of the tibiotarsus. Unguis slender, with a pair of inner proximal and one inner distal tooth. Dorsal teeth are very well developed. Unguiculus lanceo-
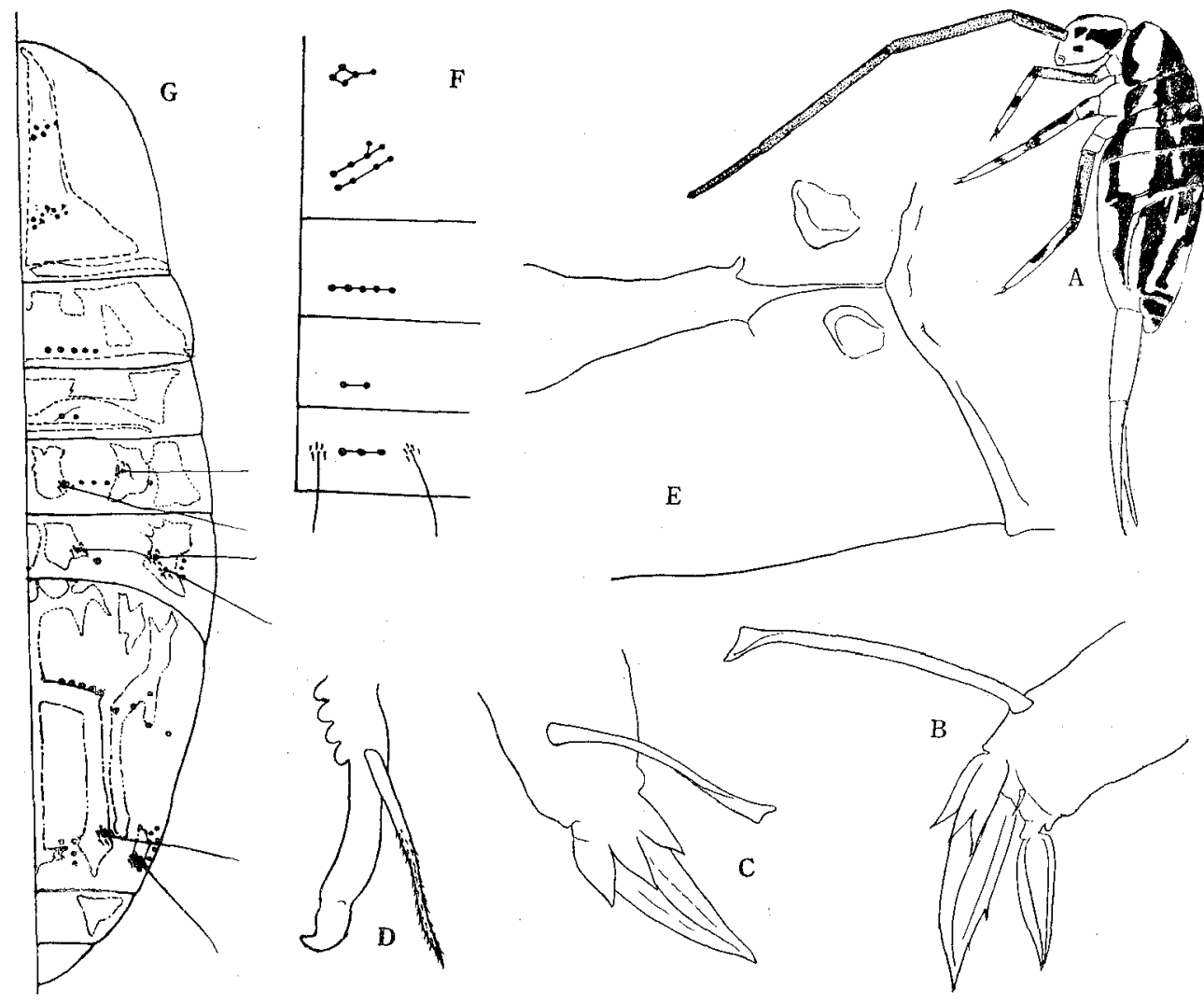

Fig. 8. Seira (Afroseira) rowani sp. n.

A. Habitus, B. C. Hind claw, D. Mucro, E. Protuberance of dentes (dorsal view), F. Chaetotaxy of body segments (diagrammatic), G. Ditto.

late, 4-lamellated and untoothed. Tenent hair well developed, longer than the unguis and broad at the end. Opposite seta is present on hind legs. Trochanteral organ is composed of about 50 densely situated simple setae. Manubrium ventrally scaled and dorsally with many ciliated setae. Dentes dorsally crenulated, laterally setaceous and ventrally scaled. Dental setae of its inner side are much elongated than any other forms of the genus and are 
almost filiform in appearance. There is not a trace of blunt claviform setae. Instead, a rounded protuberance exists to each dentes on the dorsal side near its manubrial end. Mucro is falcate as usual. Brushed body setae are poorly developed and its number is less. S. S. are accompanied by some narrow specialized scales. Specific difference of chaetotaxy appears on Th. III, where $5+5$ setae are in one straight line and on Abd. I, where setae are diminished in number.

Notes: The species is dedicated to Mrs. and Mr. Prof. RowAN of the University of Cape Town for their hospitalities and kindnesses given during my stay in the town. The species is easily distinguishable with the aforesaid characters.

\section{Seira (s. str.) pseudocoerulea (DENIS)}

(Fig. 9)

Sira coerulea: DENIS 1924.

Sira pseudocoerulea: DENIS 1924, 1929.

5 examples from Skeleton Gorge, 11. III 1958.

Body length up to $1.8 \mathrm{~mm}$. Colouration blue to light violet. Head and the proximal half of the trunk paler than the distal half of the trunk. One of my examples has the uniformly dark colouration of the body. Antennal

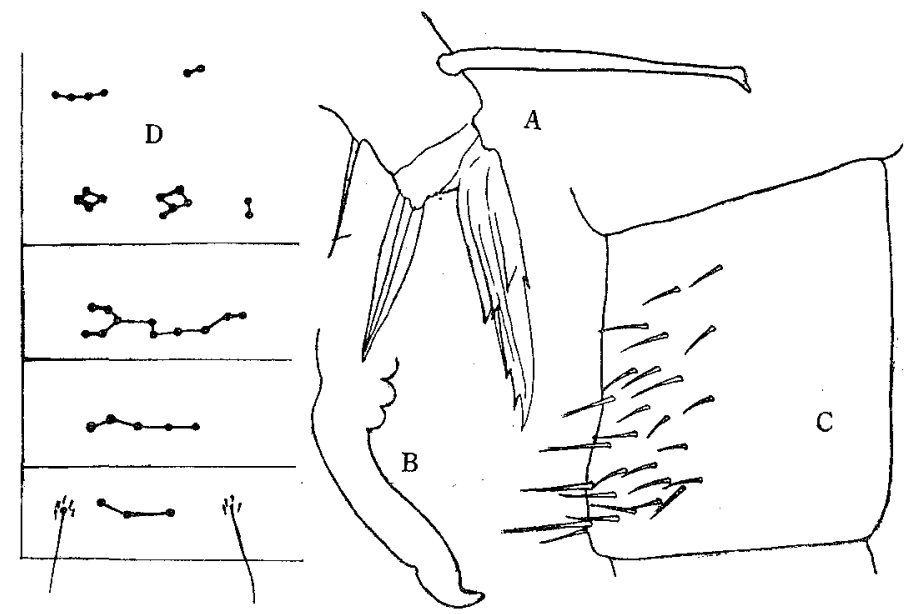

Fig. 9. Seira (s. str.) pseudocoerulea (DENIS).

A. Hind claw, B. Mucro, C. Trochanteral organ, D. Chaetotaxy of body segments (diagrammatic).

basis, eyes and fore margin of the head black. Dark pigments are also scattered along the side of the body including coxae of all legs. Femur is coloured 
on hind legs. Other extremities are paler. Antennae about 4 times the head in length. Its ratio is represented as $13: 27: 35: 35$. The distal two segments are distinctly annulated in full-grown specimens. Scales are present until to the basal part of Ant. III. Ant. IV is beset with 2 minute apical bulbs. Eyes $8+8$. Unguis and unguiculus do not differ from other members of the genus. An outer tooth of the unguiculus is either present or absent. Tenent hair well developed and broad. Its length is $5 / 4$ of the unguis on hind legs. Trochanteral organ is composed of some 20 setae. Dorsal side of the furca without modified setae and the setae are not much elongated. Dorsal crenulation is ending suddenly, leaving a smooth portion of 2.3 times the length of the mucro. Chaetotaxically, the species shows a peculiar mode of setal arrangement upon Th. II $\mathrm{m}, \mathrm{p}$ and upon Abd. I. The last-mentioned segment has 5 setae almost in a straight line with the second seta slightly proximal than others. $3+3$ setae upon Abd. II is in a slightly concaving arrangement. NoTes: The present form can be distinguished exactly only by examining the setal arrangement, just as in other forms of Seira s. str.. DENIS (1924) has described two forms of Seira from Ethiopia as coerulea and pseudocoerulea. Afterwards he (DENIS 1929) has reported the last species from Madagaskar and then put the former species to be synonymous with the latter and not vice versa. Our Cape specimens are very probably identical to these, but the Ethiopean forms must be chaetotaxically reviewed before the problem is finally settled. Pseudosira grisea of WomersLey (1933) is seemingly not synonymous with the present form, because he has described the body colour as "entirely bluish black except for the furca, tibiotarsi and apical antennal segments, which are somewhat lighter".

\section{Seira (s. str.) flavovirens (BÖRNER)}

(Fig. 10)

Lepidocyrtinus flavovirens: BöRNER 1903.

? Pseudosira grisea: WOMERSLey 1933.

2 examples from the Porcupine Buttress, 8. III 1958.

Body length up to $2.5 \mathrm{~mm}$. Colouration uniformly olive brown with some greenish tinge. Scales are intensely brown. Antennae darkly pigmented. Eye field, antennal basis and lateral margin of thoracal segments are black. Legs until to the femur, ventral tube and manubrium are somewhat dark. Tibiotarsus are lightly pigmented. Antennae long, about 3.5 times the length of the head. Antennal ratio as $17: 22: 35: 35$. It is scaled from the basis until to the proximal portion of Ant. III. Ant. III and IV are dintinctly annulated as those of S. rowani. Ant. III-organ is a pair of curved, slender sensillae inserted separately near its distal end. Ant. IV with two minute apical bulbs and numerous curving sensillae. Eyes $8+8$, two of them $(G$ and $\mathrm{H}$ ) are, however, smaller than others. Legs are beset with very well developed setae. Beside the normal feathered setae, there are two rows of spiny, finely ciliated setae on each tibiotarsus. These setae are, however, present in 
other forms in poorly developed condition. Tenent hairs are also well developed and surpasses the length of the unguis as $9: 7$ upon hind legs. Unguis normal. Unguiculus lanceolate and untoothed. Trochanteral organ well developed as in other species. Furcula elongated. Dentes is not provided with any special structure dorsally and the setae on its inner side are of moderate length. Dorsal crenulation is ending abruptly, and the mucro is falciform

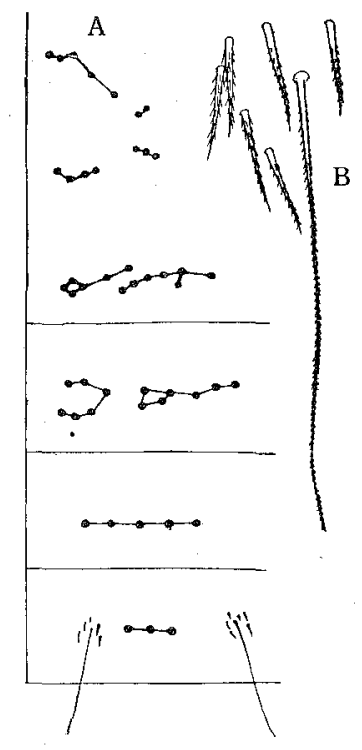

Fig. 10. Seira (s. str.) flavovirens (BöRNER).

A. Chaetotaxy of body segments (diagrammatic), B. Seta sensualis with accessory setae.

as usual. Ventral scales of dentes are hyaline, brownish in colour and variable in form. Some of them are rounded oval and others are more elongated. As the material is restricted, I was unable to investigate Abd. IV chaetotaxically, but the arrangement of brushed setae upon other segments reveals its peculiarity to other species distinctly. Very characteristic is the chaetotaxy of Th. II m, Th. III and Abd. II. Accessory setae of s. s. in this species are, in contrast to $S$. barnardi etc, not scaly but merely setaceous in form.

Notes: Pseudosira grisea WoM. (1933) might be synonymous with the present species or its darkly pigmented form. Then his S. grisea var. annulata is f. principalis of S. flavovirens.

\section{Seira (s. str.) nagatai sp. nov.}

(Fig. 11)

2 examples from Kloof Nek, 9. XII 1957.

2 examples from Kirstenbosch, 8. XII 1957.

10 examples from Skeleton Gorge, 10. III 1958. 
Body length up to $1.5 \mathrm{~mm}$. Colouration white. Antennae diffusely violet. Distal end of each segment is darker than in other parts of antennae. Antennal basis, fore margin of the head and eye field are intensely pigmented. Slightly pigmented are also the lateral margin of each thoracal segment. Other parts of the body are purely white and covered by heavily brownish

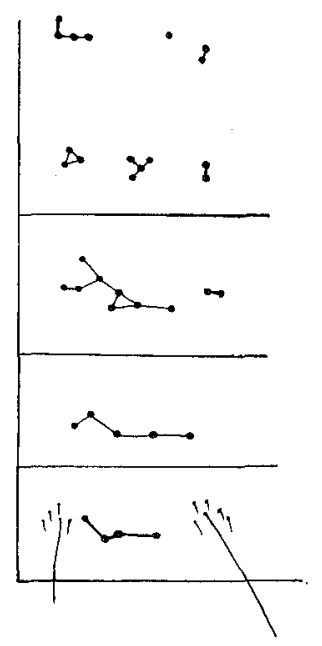

Fig. 11. Seira (s. str.) nagatai sp. n.

Chaetotaxy of body segments (diagrammatic). scales until to the proximal portion of Ant. III. All antennal segments are not annulated, but the arrangement of setae upon Ant. IV is in transverse rows. Distal antennal bulb conspicuous. Eyes $8+8$. Unguis, unguiculus and tenent hair normal for genus. Trochanteral organ feebly represented by about 20 short setae. Furca shows nothing remarkable, having no dorsal ornaments nor elongated setae of the inner side. Crenulation is ending suddenly and the mucro is falciform. Characteristic for the present species is the chaetotaxy of body segment and especially those of the Th. II $\mathrm{p}$ group, which are in three groups as $3-4-2$, forming a triangle, reversed $\mathrm{Y}$ and a bar respectively. Those of other segments are also characteristic and little variable. Those of Abd. IV is not well observed but surely of $3+3$ type of s. s. Accessory setae of these s. s. are all setaceous and not scale-like.

Notes: As the species has no peculiarity of pattern, it might be synonymous with the other forms already described. The true identity of the specimen must be made, as was stated above, only after all these hitherto described forms are studied of their chaetotaxic characters. The species is dedicated to Prof. T. NAGATA, the leader of our JARE 1957-58 party.

\section{Seira (s. str.) capensis (WOMERSLEY)}

(Fig. 12)

Lepidocyrtinus capensis: WOMERSLEY 1933.

Only two examples referable to the present species are found. As they are different in many respects, they are described separately as Example $A$ and Example B. A is a female from the Porcupine Buttress in 11. III 1958 and $B$ is a male from Kloof Nek in 6. XII 1957.

Body length $3.2 \mathrm{~mm}$ in A and $3.7 \mathrm{~mm}$. in B. Ground colour brownish white. In $\mathrm{A}$, head capsule and fore margin of mesothorax is darkly pigmented. Intensely pigmented are fore margin and median line of the head capsule. Other parts of the body including antennae are not pigmented. In $\mathrm{B}$, head capsule and Ant. I are intensely pigmented bluish purple and Ant. II-IV 
are pale. Thorax slightly pigmented along the margin including coxae of each legs. Abd. IV is also laterally pigmented reddish violet. Antennae are cut off from Ant. III distally in A and its Ant. III is inconspicuously annulated. In $\mathrm{B}$, antennae are very long, being about 7 times the head and surpassing by far the end of the body with its apex. Relative length of each segment is as $22: 30: 45: 45$. Last two segments are intensely annulated. Ant. IV with two minute apical bulbs. Ant. III organ is two rod-like sensillae. Eyes, $8+8$. Mesothorax strongly protruded over the head. Abd. IV is very long being about 7 times in $\mathrm{A}$ and 5.5 times in $\mathrm{B}$ the length of the precedent segment. Legs well beset with ciliated setae, some of them upon tibiotarsus

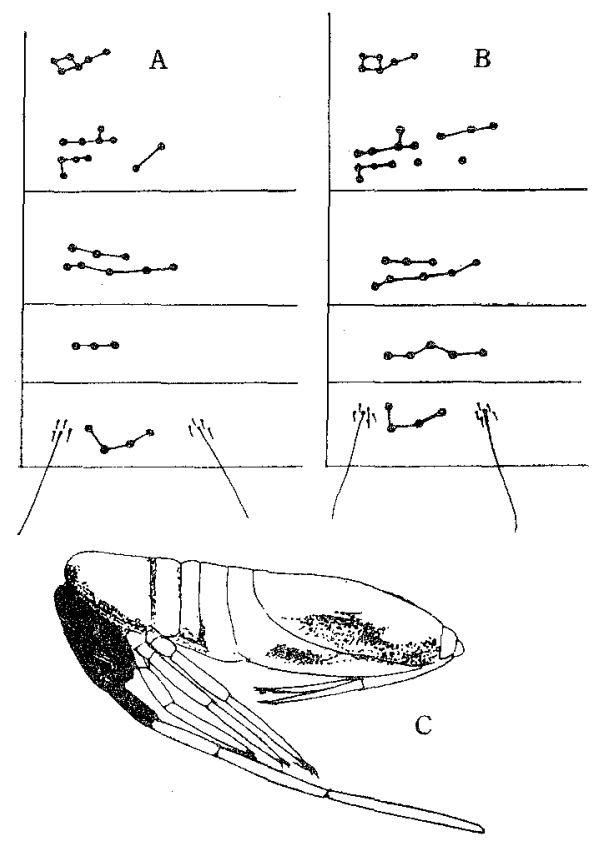

Fig. 12. Seira (s. str.) capensis (WOMERSLEY).

A. Chaetotaxy of the example A (diagrammatic), B. Ditto of the example B, C. Habitus of the example B.

are very elongated. Unguis and unguiculus, trochanteral organ and tenaculum all normal for the genus. Furcula well developed and without any special structure dorsally. Mucro falcate as usual. Chaetotaxically, the species is characterized by the queer arrangement of the setae upon Th. II p, Th. III and upon Abd. II. Those of Abd. I do not coincide in two examples at hand. A has remarkably only $3+3$ setae in a row, while $B$ has $5+5$ setae with the third seta somewhat anteriorly dislocated. From the general trend, the author supposes the case B as normal. 
Notes: There has been described various species of Seira with the dark colouration on the head: $S$. pulcher Handschin (1924) from Brasil, S. personatus (1948) from Annam, S. incertus Handschin (1926) and S. lensei DENIS (1924) from Algeria, etc. All of them must be revised with respect to their chaetotaxical characters.

\section{ADDENDUM}

Seira (s. str.) ferrarii PARONA

(Fig. 13)

Seira ferrarii: PARONA 1888.

25 examples from Casa de Campo, Madrid, XII 1945, R. YosII-leg.

Body length up to $1.8 \mathrm{~mm}$. Ground colour yellowish white and covered with brownish scales. Almost all segments of the body, excepting Th. II, are diffusely pigmented blackish blue, while Th. II is pale, having its fore

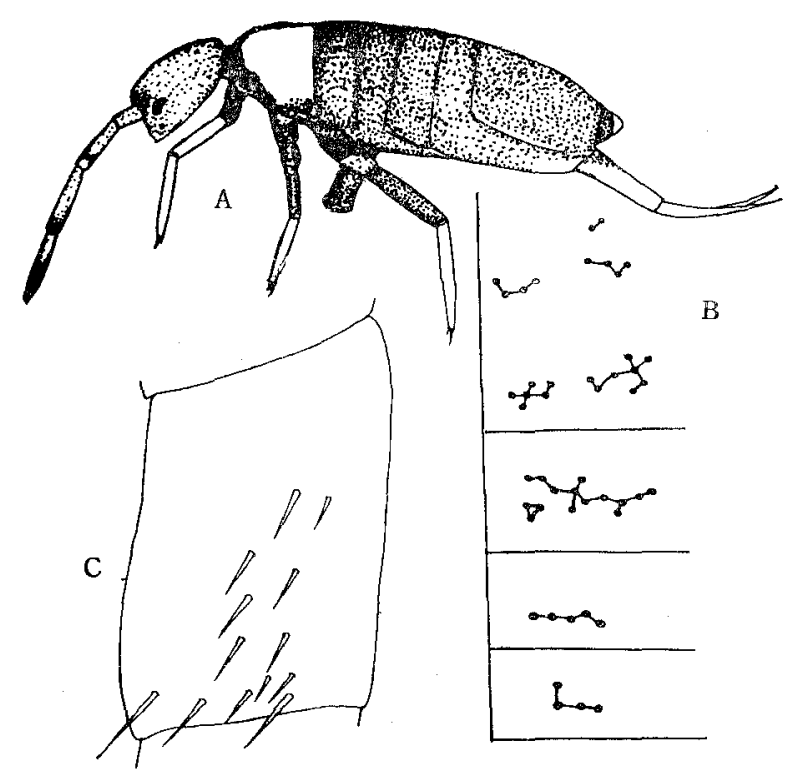

Fig. 13. Seira (s. str.) ferrarii PARONA.

A. Habitus, B. Chaetotaxy of body segments (diagrammatic), C. Trochanteral organ.

margin intensely pigmented. Antennae dark red, distally more deeply pigmented. Legs until to the femur and ventral tube also dark. Antennae twice the length of the head. Segmental ratio as $5: 10: 14: 15$. Distal two segments not annulated, but their chaetal arrangement is in rings. Eyes $8+8$. Legs 
with normal claw and tenent hair. Trochanteral organ with about 13-14 small setae. Furca without any special ornaments. Mucro falciform. Male genital area is protruded and with about 12 smaller setae. In the chaetotaxy of the body, which is represented in Fig. $13 \mathrm{c}$, the most striking is of Abd. I with its fourth seta proximally dislocated. That of Abd. II is 4 in number and in L-shape.

Notes: The species problem of Seira of the Mediterranean area was already discussed many times (DENIS 1924, HANDSCHIN 1942). For the ultimate decision the setal arrangement of S. domestica, dollfussi, banylensis etc. must be referred.

\section{LITERA'TURE}

BörNer, C. 1903. Neue altweltliche Collembolen, Sifzber. Ges. natf. Freunde, Berlin 1903: 129-259. 1906. Das System der Collembolen. Mitt. Hamb. nath. Mus. $23: 147-188$.

1907. Collembolen aus Ostafrika, Madagaskar und Sudamerika, (in) Voeltzkov's Reise in Ostafrika $2: 147-178$.

1908. Collembolen aus Südafrika, Jena. Denkschr. med. Ges. 13:51-68.

1912. Collembolen aus Zentralafrika, (in) Wiss. Erg. deut. Zentralafrika Exped. 1907-1908,

4: Lfg. $10: 283-284$

Delamare Deboutteville, C. 1954. Collemboles de Kilimanjaro, Ann. Mag. Nat. Hist. Ser. 12, 6: $817-831$.

DENTS, J. R. 1924. Sur la Faune française des Apterygotes IV, Arch. zool. exp. gén. 62 : 253-297.

1924. Sur les Collemboles du Museum de Paris, I, Ann. Soc. ent. Fr. 93:211-260.

1925. Sur les Collemboles du Museum de Paris, Ir, Ibid. 94:211-260.

1929. Sur detux Collemboles de Madagascar, Bull Mus. hist. nat. Paris 1929: 104-106.

Denis, J. R. et F. JEANNEnot 1951. Etudes d'une Population de Lepidocyrtinus domesticus. (Nic.), Suppl. Bull. Sci. Bourgogne, no. 12, 20 pp.

Folsom, J. W. 1920. Collembola of the Grave, Psyche 9: $363-367$.

1927. Insects of the subclass Apterygota from Central America and West Indies,

Proc. U. S. Nat. Mus. $72: 1-16$.

HANDSCHIN, E. 1924. Neue myrmecophile u. termitophile Collembolen aus Südamerika, N. Beitr. syst. Insektenk. $3: 13-19,21-27$.

$5: 160-177$. 1925. Contributions à l'etude de la faune de Maroc. Bull. Soc. Nat. Maroc (Rabat)

1926. Collembolen aus Algerien, N. Beitr. syst. Insektenk. $3: 117-126$.

1929. Collembola from Abyssinia, Trans. Ent. Soc. London 1929: 15-28.

1942. Collembolen aus Palästina, nebst einem Beitrag zur Revision der Gattung

Cyphoderus. Rev. suisse Zool. $49: 401-450$.

GoTo, H. E. 1952. Redescription of Choreutinula libyca, Trans. R. ent. Soc. London (B) $21: 56-60$.

Marlier, G. 1945. Collemboles du Congo Belge, Rev. Zool. Bot. Afr. $38: 251-264$.

PARONA, C. 1888. Res Ligustricae, VI, Collemboli e Thysanuri finora rincontrate in Liguria, Ann. Mus. Stor. nat. Genova (2) $6: 133-154$.

Philiptschenko, J. 1926. On the Collembola collected by the Expedition of V. A. Dogiel and I. I. Sokolow in British East Africa, Rev. Russe d'Entom. 20:180-196.

SAlMON, J. T. 1956. Collembola (in) Contributions à l'étude de la faune entomologique du RuandaUrundi (Mission P. Basilewsky 1953). Ann. Mus. R. Congo Belge (Tervuren), Zool. 51:1-40.

SchöтT, H. 1893. Beiträge zur Kenntnis der Insektenfauna von Kamerun, I Collembola, Bih. Sv. Vet. Akad. Handl. $25: 28$ pp. 7 pls.

1921. Collembola aus den Juan Fernandez und der Osterninsel, (in) Natural History of Juan Fernandez and Easter Islands, III Zool. pt. 1. Uppsala. 


\section{Riozo YosiI}

StAch, J. 1947. Apterygotan Fauna of Poland: Isotomidae; Acta monographica Hist. Nat. Krakow 1947, 488 pp. 53 pls.

- 1949, Apterygotan Fauna of Poland: Neogastruridae and Brachystomellidae, 1.c. 1949, 341 pp., 35 pls.

Stscherbakov, A. 1898. Einige Bemerkungen über Apterygogenea, die bei Kiew 1896-1897 gefunden wurden, Zool. Anz. $21: 57-65$.

WAHLgReN, E. 1906. Apterygoten aus Ägypten und dem Sudan, Inaug. Diss. Uppsala, 72 pp.

1908. Apterygogenea, In : Wiss. Erg. SjöstedT's Kilimandjaro-Meru Expedition 18:110, Taf. I.

Womersley, H. 1029. Some Records of Collembola from Southern Rhodesia, Entom. monthl. Mag. $65: 152-158$.

1933. On some Collembola Arthropleona from South Africa and Southern Rhodesia., Ann. S. Afr. Mus. $30: 441-475$. 


\section{BIOLOGICAL RESULTS}

$\mathrm{OF}$

\section{THE JAPANESE ANTARCTIC RESEARCH EXPEDITION}

1. TAnita, Senji: Sponges. 1959.

2. Nakaseko, Kojiro: On Superfamily Liosphaericae (Radiolaria) from sediments in the sea near Antarctica (On Radiolaria from sediments in the sea near Antarctica. Part 1). 1959.

$¥ 150$

3. Hirano, Minoru: Notes on some algae from the Antarctic collected by the Japanese Antarctic Research Expedition. 1959.

$¥ 150$

4. Hatai, Kotora: A new rhynchonellid (Brachiopoda) from Antarctica. 1959 . $\quad 50$

5. TokIokA, Takasi: Amaroucium erythraeum Michaelsen, a compound ascidian from the Cape Province. 1959.

$¥ 50$

6. Yosir, Riozo: Collembolan fauna of the Cape Province, with special reference to the genus Seira Lubbock.

$¥ 150$ 